\title{
Microanalysis of Carbon and Glass Fiber obtained by Resin Transfer Molding Process to Manufacture Blades for Wind Turbines
}

\author{
E. E. Vera-Cárdenas ${ }^{1}$, A. I. Martínez-Pérez ${ }^{2}$, C. Rubio-González ${ }^{3}$, S. Ledesma-Ledesma ${ }^{3}$, J. A. \\ Banderas-Hernández ${ }^{3}$, G. Luis-Raya ${ }^{2}$ \\ ${ }^{1}$ Dirección de Posgrado, Instituto Tecnológico de Pachuca, Carretera México-Pachuca Km. 87.5, \\ Colonia Venta Prieta, C.P. 42080 Pachuca de Soto, Hgo., México. \\ ${ }^{2}$ Departamento de Ingeniería Mecánica Automotriz, Universidad Politécnica de Pachuca, Carretera \\ Pachuca-Ciudad Sahagún km 20, Ex-Hacienda de Santa Bárbara, C.P. 43830 Zempoala, Hgo., México. \\ ${ }^{3}$ Centro de Ingeniería y Desarrollo Industrial, Playa Pie de la cuesta 702, Desarrollo San Pablo, \\ Querétaro, Qro.
}

Currently obtaining composite materials is of great interest for its wide variety of applications. Mainly for its resistance to high traction, hardness, chemical stability and for its flexibility [1]. In the wind industry these materials are widely used in blades, therefore the Resin Transfer Molding (RTM) process turns out to be an excellent option for its manufacture. The advantages of this process are an excellent surface finish, good thickness control, all required forms can be obtained, a wide variety of resins can be used, a short curing period, etc. [2-5]. In this work we report the microstructural characterization of carbon fiber and glass fiber in an epoxy resin matrix processed by the RTM method.

The sheets where obtained with a thickness of $4 \mathrm{~mm}$ reinforced with carbon fiber and glass fiber. It was used Epolam resin 2015 with hardener 2015. For each $100 \mathrm{~g}$ of resin $32 \mathrm{~g}$ of hardener were mixed. The injection was $17 \mathrm{cc} / \mathrm{min}$ to $50^{\circ} \mathrm{C}$; once the resin mold was filled, an injection positive pressure of 70 psi was applied for 120 minutes and the total curing time was 4.5 hours at $60{ }^{\circ} \mathrm{C}$.

Figure 1 shows the micrograph of the surface finish of the sheet of the epoxy resin matrix with carbon and glass fiber. The small particles on the surface of the samples correspond to gold aggregates, because the samples were coated with this element to be observed by SEM. The section presented in Figure 2 allowed observing the distribution of the carbon fibers inside the matrix. The Figure 3 shows the region of the surface of the matrix on which the EDS was made. The quantized elements are presented in the Table 1, which correspond to the composition of the resin and hardener used for the matrix. The results obtained confirm that the conditions of the RTM process used are adequate to obtain this type of composite materials for application in the manufacture of blades of wind generators.

References:

[1] D. Aleksendrić and P. Carlone, "Introduction to composite materials," Soft Comput. Des. Manuf. Compos. Mater. (2015) pp. 1-5.

[2] R. Sadeghian, et al, "Manufacturing carbon nanofibers toughened polyester/glass fiber composites using vacuum assisted resin transfer molding for enhancing the mode-I delamination resistance,"

Compos. Part A Appl. Sci. Manuf., vol. 37, no. 10 (2006) pp. 1787-1795.

[3] P. Ferland, et al, "Resin Transfer Molding," Polym. Compos., vol. 17, no. May (2005) pp. 32-35.

[4] K. Potter, Resin Transfer Moulding. London: Chapman \& Hall (1997) pp. 1-7.

[5] L. Fong, S.G., Advani, Resin Transfer Molding. In: Peters S.T. (eds) Handbook of Composites. Springer, Boston, MA (1998) pp. 20-21. 

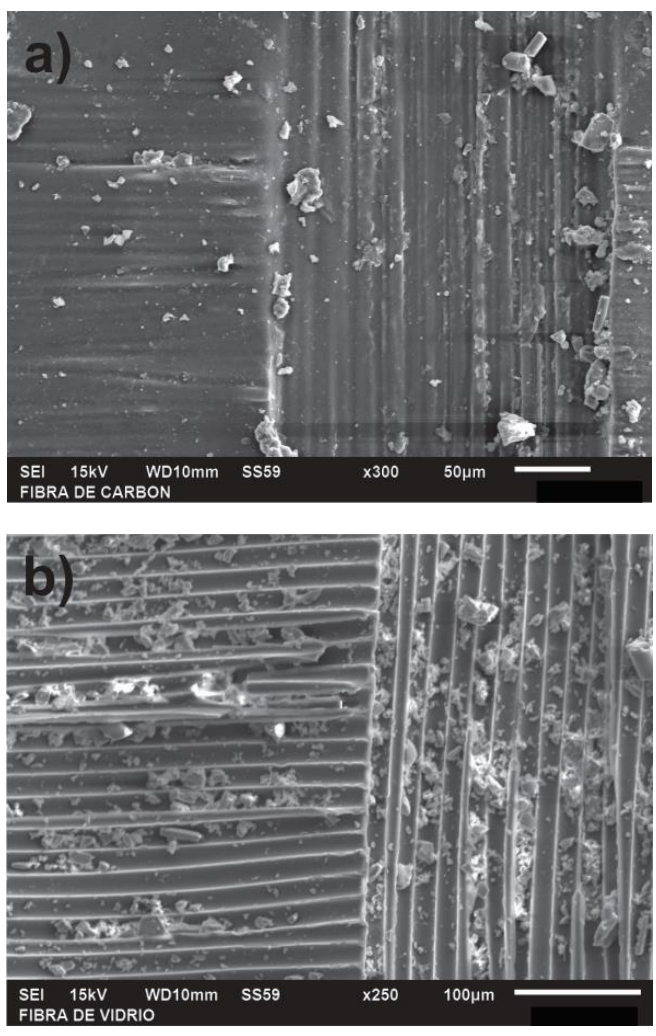

Figure 1. SEM micrograph of the surface of the resin matrix with a) carbon fiber and b) fiberglass.

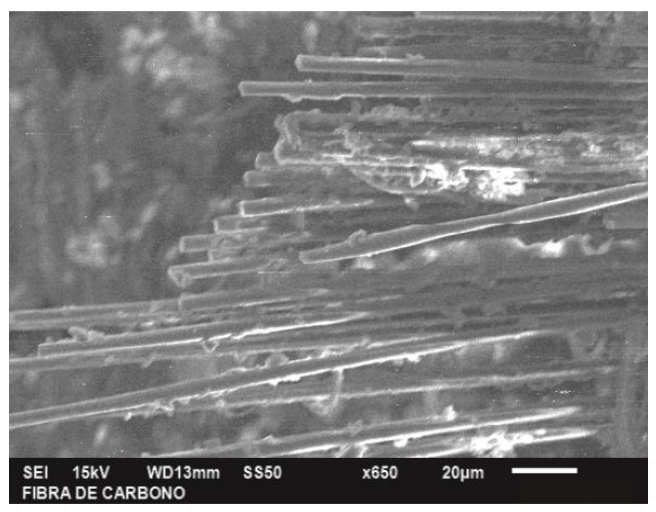

Figure 2. SEM micrograph of the epoxy resin matrix with carbon fibers.
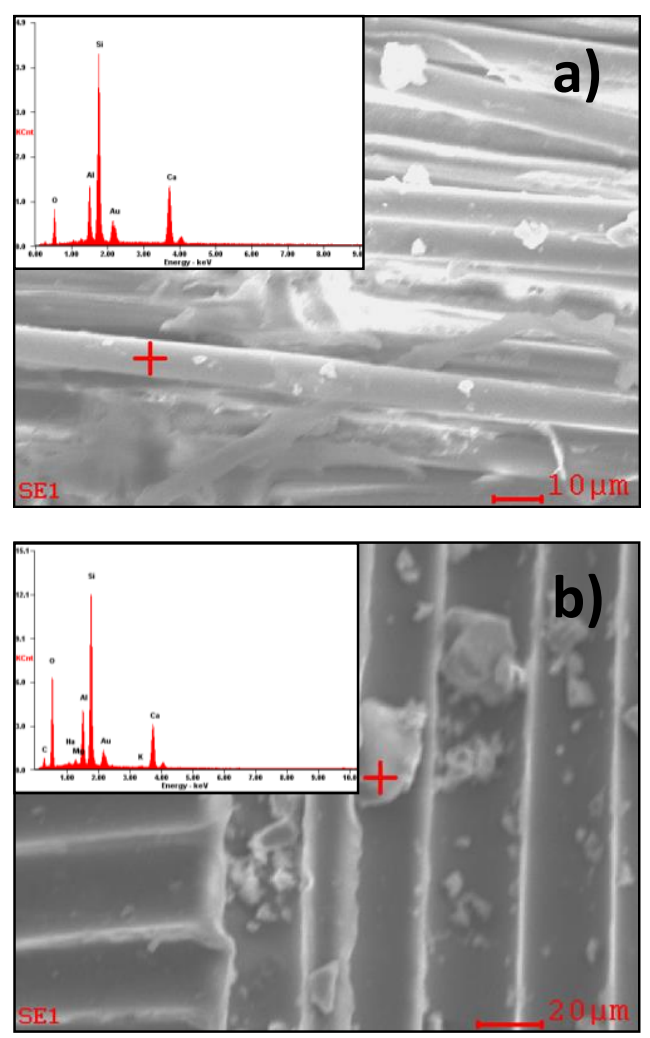

Figure 3. EDS spectrum of the matrix surface with a) carbon fiber and b) fiberglass.

\begin{tabular}{ccc}
\hline \multirow{2}{*}{ Element } & \multicolumn{2}{c}{$\begin{array}{c}\text { Sample of the } \\
\text { matrix }\end{array}$} \\
\cline { 2 - 3 } & $\begin{array}{c}\text { Carbon } \\
\text { Fiber }\end{array}$ & $\begin{array}{c}\text { Fiber } \\
\text { Glass }\end{array}$ \\
\hline \hline $\mathrm{O}$ & 15.75 & 30.71 \\
$\mathrm{Al}$ & 9.16 & 7.94 \\
$\mathrm{Si}$ & 33.57 & 28.66 \\
$\mathrm{Au}$ & 17.56 & 10.43 \\
$\mathrm{Ca}$ & 23.96 & 15.33 \\
$\mathrm{C}$ & 5.56 & 0 \\
$\mathrm{Na}$ & 0.35 & 0 \\
$\mathrm{Mg}$ & 0.61 & 0 \\
$\mathrm{~K}$ & 0.41 & 0 \\
\hline
\end{tabular}

Table 1. Chemical composition on matrix surface [wt. \%]. 